\title{
Research on Style Evolution and Development of Chinese Landscape Painting
}

\author{
Ziyi Zeng \\ Art College, Southwest University for Nationalities, Chengdu, 610041, China
}

Keywords: Style evolution, Development path, Chinese landscape painting

\begin{abstract}
Chinese landscape painting is a kind of painting which shows the beauty of the mountains and rivers and seeks the spiritual support for the human beings. From the Wei and Jin Dynasties to the contemporary era, a number of famous painters have emerged in the field of Chinese landscape paintings. They represented the style of Chinese landscape painting in every period and these styles are closely related to the social and cultural environment at that time. This paper elaborates the style evolution and development of Chinese landscape painting so as to provide some references for the relative researchers.
\end{abstract}

\section{Introduction}

Chinese landscape painting is a kind of painting based on the natural scenery of mountains and rivers. Chinese landscape painting was formed 900 years earlier than the western landscape painting of the true meaning, which has a long history of nearly more than [1]. The source of Chinese landscape painting can be traced back to the primitive society or earlier prehistoric times such as the original mural remains a primitive worship of natural scenery traces is an example in the Warring States period have been discovered in landscape painting remains and recorded as the ancient map, depicting the mountains, scenery and other crafts and so on are the carrier. Chinese landscape painting was created between the Northern and Southern Dynasties, independent of the Sui and Tang Dynasties, flourished in the Five Generations and Two Song, has gradually become the mainstream Chinese painting in three generations of Yuan, Ming and Qing. Ming and Qing Dynasties advocated the restoration of ancient times in the two dynasties. Landscape painting stagnated and declined, and the trend of prosperity was checked. At the end of Qing Dynasty, there were few bright spots in the early years of the Republic of China, but the general trend of development was fixed. Style variation China traditional landscape painting is the aesthetic orientation of the dominant, so the artist should set up the correct aesthetic view, with attention to the study of the history of aesthetic and modern social aesthetic, not only personal hobbies aesthetic style, indulge in self-admiration orientation. Although there are many changes in the history of aesthetics, it should be clear that in the field of painting, the introduction of a new aesthetic idea is not to replace the old ones with new ideas, but to enrich the connotation of paintings and increase the connotation. It is the basic requirement that a piece of work should first pay attention to its beauty. It is not enough for a good work to rely solely on the beauty of form. It should also pay attention to and reflect the beauty of artistic conception, the beauty of interest, the beauty of pen and ink, the beauty of color and so on. This kind of work is the fluent work in unity of form and spirit [2].

\section{Style Evolution and Development Path of Chinese Landscape Painting in Ancient Times}

\subsection{Style of Landscape Painting in Sui and Tang Dynasties}

The Spring Outing Map painted by Zhan Ziqian in Sui dynasty was the earliest known today's landscape painting. Zhan Ziqian was good at painting in various categories, characters, landscape and horses are exquisite. "Spring outing" is a depiction of natural scenery in the green landscape, showing people the spring travel scene. The painter in the little silk banners with proper management, fine brushwork and fresh colors, painted in the emerald castle, verdant trees, glittering spring series. The surface water filled the air, in the picturesque scenery, the glittering lake, a magnificent high sail yacht with the waves. A three woman to look around, revel in the bright as a landscape of lakes and 
mountains. The shore and mountain trail, the number of people or riding or walking, sitting or standing, interest. The painter through the depiction of the natural scenery and the characters vivid, successfully perform the theme of "spring outing". "Spring outing" for the formation of the Tang Dynasty landscape painting opened the curtain. As for the Tang Dynasty, Li Sixun and his son Li Daozhao directly inherited the style of Zhan Ziqian in Sui dynasty. Li Sixun's pen work was rigorous, strong color sound, picture pattern of the grand, stately gorgeous, adornment sex is very strong. $\mathrm{Li}$ Daozhao inherited his father's painting and created the landscape of sea landscape. The source of another landscape painting school - ink and water landscape painting also appeared in the Tang Dynasty. Wang Wei is the founder of the Chinese landscape painting, is Chinese cultural history of the rare all-rounder, Jingshan poetry, painting, music. Wang Wei's painting liked to use the snow scenery, the trestle road, fishing and so on, which has the characteristics of heavy and exquisite brush and ink [3].

\subsection{Style of Landscape Painting in Two Song Dynasties}

The central plains painting and the school courtyard landscape appeared in the Northern Song Dynasty [4]. The central plains painting is represented by Li Cheng and Fan Kuan. Li Cheng moved to Shandong to Camp Hill, often in the fields of Qilu natural environment as depicted object. The wide range of long-term residence in Zhongnanshan and Huashan, his paintings Chongshan strong, towering rock, lush forests, imposing. After the unification of the Northern Song Dynasty, the painters in the south of the Yangtze river went up north and were courteous to the Northern Song Dynasty painting academy, which impacted the Northern Song Dynasty landscape painting which was centered on the Central Plains painting school. The north and South painting school began to merge, forming the courtyard landscape painting represented by Guo Xi. But in the early Five Dynasties of Song Dynasty, this school painting was not regarded as a scholar bureaucrat painter, and was a professional painter's craftsman, and was once depressed. The Northern Song Dynasty, some painters Lipaizhongyi, committed to the green landscape, to create a palace for the taste of the green landscape painting, which entered the mature period, on behalf of the artists Wang Ximeng and Zhao Boju. The Southern Song Dynasty established the Southern Song Dynasty Painting Academy in the Southern Song Dynasty. Due to the change of politics and life in the North South painter, Southern Song Dynasty painting from content to style has changed, with Li Tang, Liu Songnian, Ma Yuan and Xia Gui as the representative of the Southern Song Dynasty landscape painting academy. The landscape painting in the Southern Song Dynasty is distinctly different from the landscape painting in the Northern Song Dynasty. Since the Northern Song Dynasty, the artist abandoned the high mountain torrent composition and the meticulous and complicated brush and ink centered on the main peak in the Northern Song Dynasty, and the innovation was a simple and simple form. The two diagonals far and near control method is used to form diagonal composition, so that the center of gravity of the picture deviates from the middle and is in the half corner. Some artists not only patriotic aspirations blighted, they see the treasures of ancient dynasties paintings looted, the capital of Southern Song Dynasty dance without scene, but not to the Southern Song Dynasty and shortened the landless determination and action. They exhibited complex mood mapping of society in the work of the theme, layout and writing.

\subsection{Style of Landscape Painting in Ming and Qing Dynasties}

Except for the minority painters, most painters in Ming and Qing dynasties were good at imitating the ancient painter for the gallery, to increase interest ink pen. As of early Ming Dynasty painting in the Southern Song Dynasty art academy, advocating the Zhejiang based. But after painting, is a breakthrough, they emphasize subjective aesthetic feelings, into each of the long, flexible tactics, the composition does not follow from the traditional format to the free arrangement, emphasizes the delight of life. Shen Zhou created a variety of style of landscape painting, some fine, some rough, some magnificent, some. There is a panoramic view of the alpine mountains, also have pastoral scenery. The simple technique, rich life means. His landscape painting has two kinds of specifications, such as brushwork and freehand brushwork, freehand brushwork and ink and wash, and ink and wash. Meticulous landscape, but not stereotyped, has a typical book and literary tastes. Tang Yin's paintings 
were taken by Li Cheng, Fan Kuan and the four big painters in Southern Song Dynasty, and the law of the Yuan Dynasty and the length of the family. The work style of rigorous, grand scenes and run the show, is both strong and Rao in flavor characteristics. Qiu Ying was born with the painter status, but he is not a scholar, was influenced by the literati painters and folk artist in the art of painting, so he put these two aspects of integration, has also been high approval literati scholars, with the tastes of artistic taste. The different factions of Chinese landscape painting, to the Qing Dynasty, is also very unique. The Qing Dynasty is an important period in the history of Chinese art. There are new changes in the art ideology, creative attitude and artistic style of the literati system, which is also accompanied by the changes in the political and ideological culture at that time. Since the Qing Dynasty rulers adopted a policy of cultural autocracy and close the country to international intercourse to consolidate the peasant economy and depress the commodity production.

\section{Style Evolution and Development Path of Chinese Landscape Painting from Modern Times}

\subsection{Style of Landscape Painting in Modern Times}

The development of modern Chinese landscape painting is not optimistic. This is related to the bondage and self-closure of the Chinese feudal cultural tradition. It has its own system. The traditional concept, stylized framework, single carrier and other comprehensive factors have restricted the development of modern and modern landscape painting. The development of modern Chinese painting art is in a period of great convergence between eastern and Western civilizations. The painting is diverse, the development trend of the three-dimensional multipole, arranged in a crisscross pattern. The development of plastic arts, the penetration of interdisciplinary subjects and the accompanying generation of installation art, the development of computer art and the influx of other comprehensive arts are the best evidence. The concept of modern landscape painting and the change of Chinese universe consciousness, imitating nature, return to life. The specific image weakening, unified to the essence of the simplest, is the general trend of painting style development, is a kind of rebellion against the traditional literati painting of the great change, the new style, the new school of painting are constantly emerging, unprecedented active, famous men. From Xianfeng, Zhejiang painter gradually gained the upper hand. In the period of Tongzhi, a school of Shanghai formed. Most of the painters of the Shanghai school are from the lower level of the society and have a link with the folk art. To preserve their national dignity, inheriting the excellent traditional culture, poetry, books, paintings, printing as one of the traditional literati painting and traditional folk art and Western painting will combine into traditional, and absorb nutrients from the ancient stone art, depicting popular folk themes, show the times and life style, the formation of new the pattern of tastes. It broke through the barriers of the Qing Dynasty's two hundred years rule of landscape painting, which was accepted by the society from all walks of life and influenced on Chinese painting to a great extent.

\subsection{Style of Landscape Painting in Contemporary Times}

The collision between the traditional oriental civilization and the modern western civilization will lead to sparks. It may also change the old cultural system in the process of blending and absorption, and will encounter such or such problems, and can produce great shock. In this change, blending, new works, new techniques and new generation artists emerge in an endless stream, is on the rise, the content and form of exploration works greatly improve, showing the characteristics of free and diverse, more and more artists cluster, explore the pure art and pure reason than ever with random, single and the pursuit of one sidedness. More painters do not pass a single piece of work, but show the author's own value through many works. In the early twentieth Century, the national crisis was unprecedentedly serious, and the western culture spread to a large scale. Chinese people had undergone tremendous changes in their ideological culture. The traditional landscape painting was severely impacted. Kang Youwei suspected Chinese traditional Chinese painting, which was not sparse shallow, realistic than western painting. Chen Duxiu criticized the traditional literati painting. Since then, in the rapid and violent social and political reform and ideological and cultural turmoil, 
the traditional landscape painting is unavoidable. In twentieth Century the new culture movement, the introduction of western realism to enlighten the people, promote social service reform needs democratic enlightenment. Until today, western realism in the field of art still has a special existence value and significance, as well as strong vitality. Although the traditional landscape painting is in a state of decline, it does not die out. The quintessence protectionist always adheres to the pure traditional landscape painting method, and Zhang Daqian's landscape painting was also the product of the variety of this painting method. Huang Binhong and Zhao Wangyun concentrated on the traditions and protecting their creativity in a personalized way.

\subsection{Style of Landscape Painting in Present Times}

Many immortal masterpieces have been created among many contemporary artists of exploration, and great achievements have been made in the development of landscape painting in the new period. However, the contemporary Chinese painting, reflecting the real life enough to represent the spirit of the times of the works too little. Insipid, serious repeated work too much, put all sorts of things together. Most of the landscape painters also repeat the various techniques and characteristics that have reached the peak of the masters of the past dynasties. Chinese paintings of characters, flowers and birds, in the landscape, landscape painting is always the mainstream. Only the change of landscape painting is the change of Chinese painting in the real sense. It thinks that academia is thought. A real understanding of Chinese painting should dig its connotation from the traditional spirit. Only by the change of Chinese landscape painting can we change from the traditional Chinese painting to the modern landscape painting. Lin Fengmian is quite different from Huang Binhong, and it is mainly a new discovery of the line. The line as a means of emotional brushwork, online approaches to achieve the perfect fusion of Chinese and Western extreme, like celadon elegant, bright and clean, through the Chinese ancient art and modern art channel, has great effect on Chinese landscape change. They go through two different levels of landscape sketching and scenery creation. Their creation is not only the change of writing style, but also the change of composition, the change of nature, the change of image. Their paintings come from life, but they are not only the image of natural life, but a kind of objectified generalization and refinement. The modern landscape painters attach great importance to life. Contemporary artists both in the macro grasp of the natural mountains and rivers in the mud in nature really see the visual landscape, give full play to the initiative of the author, who focuse on the scene, the freedom of expression of the painter's artistic experience and spiritual world.

\section{Conclusions}

Chinese landscape painting should go towards the modern form and have modern characteristics. In general, the classical form of Chinese painting should be different from the western modernist. It also embodies the modern Chinese spirit of the times with an open attitude, and widely absorbs the essence of ancient Chinese landscape painting and modern Chinese landscape painting. To clarify the development grain of Chinese landscape painting style is of great benefit to the development of Chinese landscape painting.

\section{References}

[1] Feng Jie. Influence of Cultural Ideas of Song Dynasty on Composition of Landscape Paintings [J]. Journal of Taiyuan Normal University (Social Science Edition), 2017, 16(1): 104-106.

[2] Xie Fangkai. New Artistic Conception In Chinese Ink Landscape Painting [J]. China Population Today, 2015(2): 44-45.

[3] Xie Jian. The Space Consciousness in the Landscape Paintings in the Five Dynasties in Jiangnan Region and the Artistic Style of Southern Tang Ci-poetry [J]. Lantai World, 2017(22): 91-94.

[4] Li Huarui. The Social Transformation of Southand North Song Dynasty and the Style of Landscape Paintings [J]. Journal of Henan University (Social Science), 2012, 52(1): 65-72. 